\title{
Optimization of Shareholders' Incomes with Investments into Production Reforming
}

\author{
Lyudmila N. Rodionova ${ }^{1}$, Olga G. Kantor ${ }^{2}$, Natalia O. Ruhlyada ${ }^{3}$, Svetlana \\ A. Karpovskaya ${ }^{4}$
}

\begin{abstract}
:
In recent years a company's goal is not profit making but capitalization. Companies having the capital value larger than their competitors win in the market. This determines the trends in the capital market, namely merger and acquisition, which have been very popular recently in the international market.

This paper considers economic statement, formalization and fulfillment of a problem of optimization of management decisions during formation of funds for company development.
\end{abstract}

Key Words: distribution of profits, dividend policy, market capitalization, the optimization, method of successive concessions

JEL Classification: D53, E44, G14

\footnotetext{
${ }^{1}$ Ufa State Aviation Technical University, Ufa, Russia E-mail:m.rodionova.2016@mail.ru

${ }^{2}$ Institute of Social and Economic Research, Ufa Scientific Centre of Russian Academy of Sciences

${ }^{3}$ St.-Petersburg State Polytechnical University Peter the Great

${ }^{4}$ JSC Gazprom neft
} 


\section{Introduction}

In the conditions of market relations development the government does not state any standards for profit distribution. But it stimulates movement of profit to capital investments of productive and non-productive character, charitable purposes, environmental measures financing, maintenance of social facilities and institutions via granting tax exemptions.

Distribution of net profit is one of the directions of corporate planning. In accordance with the RF legislation and charter documents, at the first stage the organization, if it is envisaged by the organization charter, builds a surplus fund. The surplus fund is used to cover damages and other unforeseen costs, pay dividends in case of profit lack, cancel credit indebtedness in case of liquidation of organization.

After the profit is contributed to the surplus fund, the organization (wealth holders or shareholders) forms consumption and accumulation funds irrespective of its business legal structure.

\section{Literature Review}

In the late 70's-early 80-ies were published the results of researches R. Litzenberger (1978) and K. Ramasvami (1982) which later were called tax differentiation theory, according to which, from the position of shareholders priority, meaning has not dividend yield but capitalized earnings value. The explanation for this is quite obvious - the income from the capitalization was taxed at lower rates than dividends. Tax rates were changing periodically but in any case the difference between them remained. According to this theory, if two companies differ only in the methods of profit distribution the shareholders of the company who have a relatively high level of dividends should require higher earnings per share to compensate losses with increased taxation.

Thus, this is not profitable for the company to pay high dividends, and its market value maximizes at a relatively low share of dividends in the profit. In addition the most of countries have tax differentiation in respect of tax payments; it also affects preferences of this or another group of investors in respect of a share reinvested profit.

Overview of this aspect of dividend policy in international context can be found, for instance, in the book of R.A. Bredley and S.C. Myers (1997) Research published by J. Lintner in 1956 year laid the foundation of dividend policy in economic science. In which, on the basis of 28 firms in the US, the author concluded that the large companies whose growth potential is significantly limited have the greater propensity to dividend payment. They regularly pay dividends, and their value is adjusted from year to year slightly. Based on this work development started two 
theories of dividends, first of all, agency and signaling theory of dividends. Suppose that the first authors of signaling theory were S. Ross and S. Bhattacharyya (1979).

Stern (1974) believed that signaling theory is too expensive for the company. G. Grullon., R. Michaely and B. Swaminathan (2002) proposed a hypothesis of enterprise's maturity, which implies that the company, when entered into a phase of maturity, reduces it investment opportunities, so realizing spare cash which could be paid as dividends. M. Jensen and W. Macklin (1976) formulated Agent theory in 1976 as conflict of interests between shareholders and managers. F. Easterbrook proved that payment of higher dividends leads to higher transparency of senior management work for shareholders and, accordingly, the ability to control increase. In the case of "weak" shareholders senior management of the organization can start to solve their own tasks, could be even stealing, instead of increasing the company's capitalization and shareholder's wealth. Possible conflict of interests between shareholders and creditors was proved empirically in the paper of G. Handjinicolaou and A. Kalay in 1984.

At the same time it should be noted that there is a distinct contradiction in earning an income in the form of capital interest increase, namely dividends, or with retained interest in the form of the company's capital increase. In recent years the company's goal is not profit making, but capitalization. Companies having the capital value larger than their competitors win in the market. This determines the trends in the capital market, namely merger and acquisition, which have been very popular recently in the international market. The capital increase interest is a "strategic" income; traditional dividends are a "tactical" income.

\section{Results and Discussion}

This requires optimization of decisions during formation of funds for company development, and, therefore, capitalization growth to the prejudice of short-term interests like considerable dividends.

Let us introduce the symbols.

$t-$ year, $t=\overline{1, T}$;

$K_{t}$-capital assets of an enterprise in the $t$-th year;

$V_{t}$-current assets of an enterprise in the $t$-th year;

$n_{t}$ - rate of amortization deductions of an enterprise in the $t$-th year;

$A_{t}$ - amortization deductions of an enterprise in the $t$-th year;

$P_{t}$-net profit of an enterprise in the $t$-th year;

$I_{t}$ - outward investments in an enterprise in the $t$-th year;

$\alpha_{t}$ - part of amortization deductions of an enterprise in the $t$-th year used for recovery of capital assets; 
$\beta_{t}^{l}$ - net profit share of an enterprise in the $t$-th year used for recovery of capital assets;

$\beta_{t}^{2}-$ net profit share of an enterprise in the $t$-th year used for recovery of current assets;

$$
\begin{gathered}
i \text {-discount rate; } \\
j \text {-inflation rate. }
\end{gathered}
$$

Basing on the introduced symbols, capital and current assets of an enterprise can be calculated according to the following formulas:

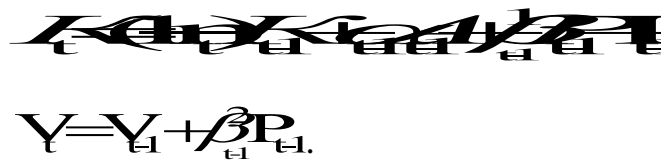

Let us suppose that the enterprise operates successfully, if its capital and current assets increase annually minimum by $\Delta \%$ with account of discounting and inflation. This requirement shall be formalized as the following inequations:

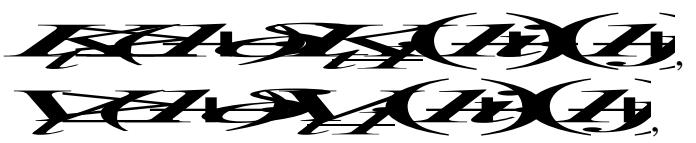

where $\delta=410$. It should be noted that the higher $\delta$ is, the more successful is the enterprise.

Let us transform the formula account the fact that the addend $i j$ has a significantly lower order of vanishing as compared to others, let us simplify formulas (3) and (4):

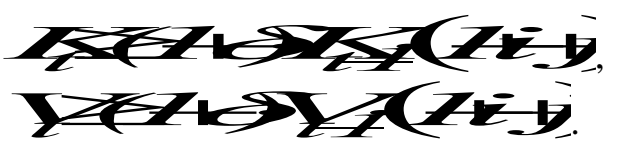

With account of formula (1), supposing that the net profit of the enterprise is positive, let us transform expression (5):

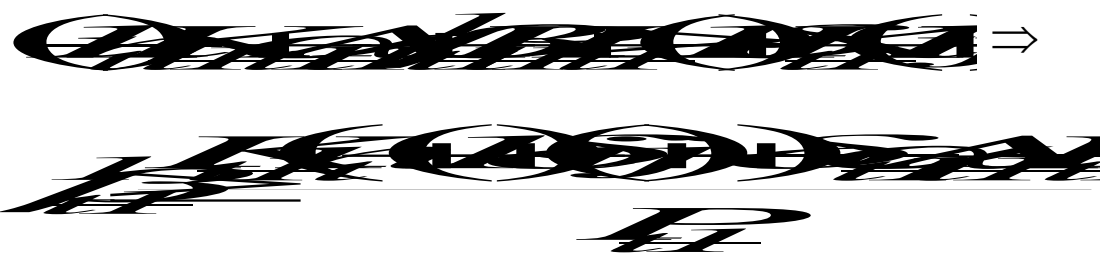


It is seen from expression (7) that in order to determine the $\beta_{T}^{l}$ value, it is necessary to set the rate of amortization deductions of the subsequent time period $n_{T+1}$, which is not difficult in itself.

In a similar the $\beta_{t-1}^{2}$ value shall be expressed with the help of formulas (6) and (2):

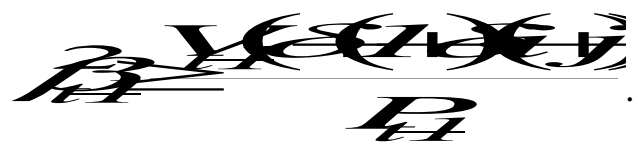

It is evident that

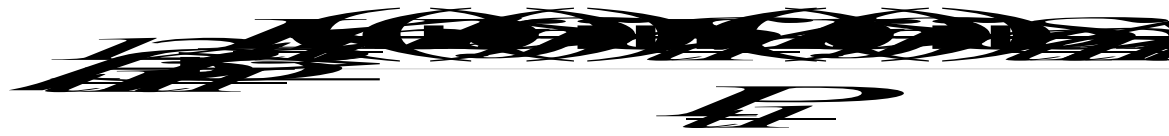

The last formula demonstrates what share of the net profit $(t-1)$ of the year should be contributed into the recovery of capital and current assets, so that the enterprise could be considered as successful in the $t$-th year. Alongside with that the rest of the net profit should be sufficient not only for dividends and incentive payments but also for establishing accumulation funds. Let us consider that the minimum allowable limit for the net profit share used for establishing funds for stimulation and production development makes $15 \%$. Then the net profit share $\gamma_{t-1}$, used in the $(t$ 1)-th year for paying dividends and incentives, can be calculated according to the equation:

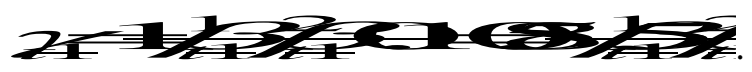

It proceeds from the last equation that:

$$
\beta_{1}+\beta_{1} \leq 08
$$

Let us consider that the net profit share applied for recovery of capital assets cannot be lower of the set limit taken as 0.1 . This requirement is evident, if the enterprise conducts a policy of production reforming. Thus,

$\beta_{t-1}^{1} \geq 0.1$

The aim of shareholders is to draw a maximum sum of dividends and incentives, which with account of discounting and inflation can be formalized in the following way: 


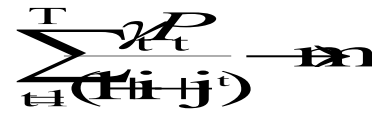

It should be noted that function (13) reaches its maximum, if expressions (7) and (8) are satisfied as equations.

When determining the long-term program for enterprise development, it is practically impossible to set all the $I_{t}$ values, which characterize the volume of outward investments into the enterprise. Therefore, it is important to know the volumes of outward investments, in order to ensure increment of capital and currents assets at the set level $\delta^{0}$ with fulfillment of previously formed assumptions and conditions. Therefore, all the values $I_{t}, t=\overline{1, T}$ shall be considered as unknown.

In the stated assumptions mathematical setting of a problem of optimization of shareholders' incomes with investments into the production reforming has a view:
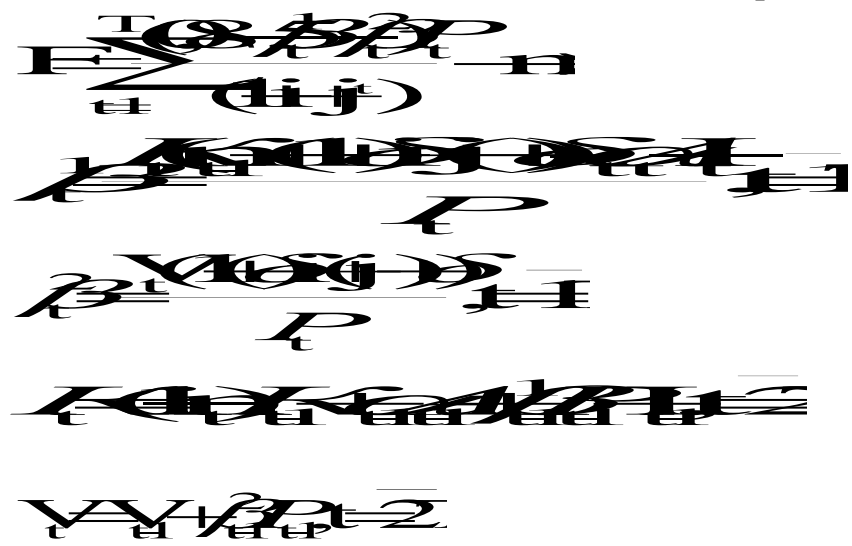

$\beta \geq 01, \overline{17}$

$\beta \geq \mathrm{Qt}=\overline{1, \mathrm{I}}$

$13+, 3+2,15 \overline{1}$

$\delta \geq \delta^{0}$

$K_{1}=K^{0}$

$\mathrm{V}_{1}=\mathrm{V}^{0}$

$$
\mathrm{O}<x \leq 4 \mathrm{TI}
$$


In equations (14-25) the values $\alpha_{t}, I_{t}, t=\overline{1, T}, \delta$ are variables. In order to settle problem (14-25) the following parameters should be known: $T, i, j, n_{t}$, $A_{t}, \quad P_{t}, t=\overline{1, T}$. The advantage of model (14-25) is possibility to determine a long-term program for enterprise development, which ensures the set level of capitalization on the basis of calculation of owner's investments into the production development and required investments. Direct realization of the model can be performed with account different variants of amortization deductions (via setting the values $n_{t}, A_{t}, t=\overline{1, T}$ ), which will enable enhancing the effectiveness of taken decisions.

Practical realization of the model was performed on the basis of the enterprise operation rate. A five-year period was taken as calculation period $(T=5)$; discount and inflation rates were taken at $12 \%$ and $8 \%$ respectively; the annual standard of amortization deductions was taken at a level of $15 \%\left(\boldsymbol{n}_{t}=0.15, \boldsymbol{t}=\overline{\mathbf{1}, \boldsymbol{T}+\boldsymbol{l}}\right)$; $K^{\Theta}=205$ Mln rubles; $V^{\theta}=140$ Mln rubles.

Table 1. Predictable enterprise operating rates, Mln rubles

\begin{tabular}{|l|l|l|l|l|l|}
\hline Year & 1 & 2 & 3 & 4 & 5 \\
\hline Net profit & 53994 & 59888 & 69385 & 73338 & 86629 \\
\hline Amortization deductions & 3375 & 4045 & 4653 & 5535 & 6136 \\
\hline
\end{tabular}

In the course of realization of model (14-25) different variants for setting the minimum level of $\delta^{O}$ increment of capital and current assets were considered. Additional condition for the values of the part of amortization deductions used for recovery of capital assets $\alpha_{t} \leq \alpha^{O}$ was introduced, which was conditioned by the necessity of accumulation of amortization deductions.

Table 2. Results of numerical implementation of the problem aimed at optimization of shareholders' incomes with investments into production reforming

\begin{tabular}{|l|l|l|l|l|l|}
\hline Year & 1 & 2 & 3 & 4 & 5 \\
\hline Variant 1 $\left(\delta^{0}=0.04, \alpha^{0}=0.8\right)$ & 0.8 & 0.8 & 0.8 & 0.8 & 0.8 \\
\hline$\alpha_{t}$, shares & 73490.65 & 66257.0 & $\begin{array}{l}116415 . \\
9\end{array}$ & $\begin{array}{l}110157 . \\
0\end{array}$ & 93250.3 \\
\hline$I_{t}$, Mln rubles & 0.04 & & \\
\hline$\delta$, shares & 90007.36 \\
\hline Objective function, Mln rubles & Variant 2 $\left(\delta^{0}=0.06, \alpha^{0}=0.8\right)$ \\
\hline
\end{tabular}




\begin{tabular}{|c|c|c|c|c|c|}
\hline$\alpha_{t}$ & 0.8 & 0.8 & 0.8 & 0.8 & 0.8 \\
\hline$I_{t}$, Mln rubles & 78410.65 & 88680.13 & $\begin{array}{l}129310 . \\
9\end{array}$ & $\begin{array}{l}122321 . \\
6\end{array}$ & $\begin{array}{l}103564 . \\
0\end{array}$ \\
\hline$\delta$ & \multicolumn{5}{|l|}{0.06} \\
\hline Objective function & \multicolumn{5}{|l|}{88489.63} \\
\hline \multicolumn{6}{|c|}{ Variant $3\left(\delta^{\Theta}=O, O \varepsilon, \alpha^{O}=0,8\right)$} \\
\hline$\alpha_{t, \text { shares }}$ & 0.8 & 0.8 & 0.8 & 0.8 & 0.8 \\
\hline$I_{t}$, Mln rubles & 83330.6 & 76128.8 & $\begin{array}{l}142906 . \\
5\end{array}$ & $\begin{array}{l}141964 . \\
3\end{array}$ & $\begin{array}{l}114462 . \\
0\end{array}$ \\
\hline$\delta$, shares & \multicolumn{5}{|l|}{0.08} \\
\hline Objective function, Mln rubles & \multicolumn{5}{|l|}{65122.99} \\
\hline \multicolumn{6}{|c|}{ Variant $4\left(\delta^{O}=0,1, \alpha^{O}=0,6\right)$} \\
\hline$\alpha_{t}$, shares & 0.6 & 0.6 & 0.6 & 0.6 & 0.6 \\
\hline$I_{t}$, Mln rubles & 88925.6 & 81173.1 & $\begin{array}{l}158149 . \\
9\end{array}$ & $\begin{array}{l}179550 . \\
6\end{array}$ & $\begin{array}{l}152004 . \\
7\end{array}$ \\
\hline$\delta$, shares & \multicolumn{5}{|l|}{0.1} \\
\hline Objective function, Mln rubles & \multicolumn{5}{|l|}{65539.78} \\
\hline
\end{tabular}

The analysis of the calculation results showed that under the existing structure of capital and current assets of the enterprise and predictable operating rates for 5 years (Table 1), in order to achieve the set level of capitalization of capital and current assets $\delta^{0}$, it is necessary to apply annual amortization deductions and attract outward investments, which exceed the enterprise net profit. This is quite uneasy, taking into account the current economic situation.

The obtained results testify to domination of shareholders' interests, who often tend to draw income immediately without taking care of the enterprise's future. As a result at the end of the 5-year period there can happen a rather complicated situation caused by an insignificant amount of accumulated amortization deductions. This will not allow the enterprise renewing the existing assets. It should be noted that interests of the enterprise manifest themselves first of all in the capitalization growth of capital assets, which contributes to increase of the shareholders' (emitters') incomes though with some delay. This fact conditions the main contradiction between the interests of shareholders and enterprise, which can be formalized in the following way:

$$
K=\frac{K_{T}}{K_{1}} .
$$


Another criterion describing the enterprise operating efficiency along with the mentioned $\delta$ parameter can be considered the value of accumulated amortization fund with account of discounting:

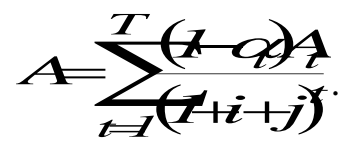

It should be noted that the development strategy that could ensure all the criteria $(F$, $K, A, \delta$ ) achieving their maximum values would be ideal both for the enterprise and shareholders. However, it is impossible to achieve in practice due to evident inconsistency of the criteria $F$ and $K, F$ and $\delta, K$ and $A$. Application of special techniques for settling multicriterion problems turns to be reasonable in this connection. It is fair to mention that settling of mutlicriterion problems is a rather complicated task. The most well-known and widely used methods for settling multicriterion problems are generalized criterion method, main criterion method, method of sequential concessions. The first and the second method are one-step methods, and the third one is a multi-step method.

All these methods are connected with a common way of decision making: a vectorvalued criterion is transformed in some way to the scalar target function, and then the optimization problem is settled. It is anticipated that a decision-maker can provide all the necessary information for describing the aggregate function.

In the method of generalized criterion partial criteria convolute into the scalar function with the help of weight coefficients set by a decision-maker. Then the scalar function maximizes (minimizes) with the aim of finding an optimal alternative.

The main point of the method of sequential concessions (Podinovskiy and Gavrilov, 1975) is that after qualitative analysis of relative importance of the criteria the multicriterion optimization problem resolves itself to successive solution of onecriterion problems. The problem with the most important target criterion is to be solved first. Then the problem having the target function as a second important criterion shall be settled next. One more restriction is added to the set of feasible solutions of the second problem. This restriction reflects the requirement according to which the criterion first in order of importance should not be lower than some limit value (in other words, a "concession" is set for this criterion), etc. In each subsequent problem a set of restrictions will have one more inequation. Thus, the compromise is reached, when the number of iterations coincides with the number of criteria of initial multi-criterion problem.

Order of importance of criteria and setting of concession values are main requirements for the method of sequential concessions. Due to the fact that 
concessions are set arbitrarily at the discretion of the decision-maker, the latter may lead to the degenerate set of feasible solutions. In this case it is necessary to get back to the previous iterations and reconsider the values of concessions according to the criteria.

Unlike the generalized criterion method, the main criterion method does not require describing the aggregate function on partial criteria. Aggregating resolves itself to designation of one of the criteria as the main one, which lightens the work of the decision-maker.

With the aim of elimination of mistakes made by the decision-maker when designating criteria weight, the generalized criterion method was not used. The method of sequential concession was also excluded from consideration due to difficulties in setting the concession values.

In this work a two-stage procedure of solution making was applied. At the first stage the main criterion was chosen (the parameter $\delta$ was taken as the main criterion, as it secures annual increment of capital and current assets of the enterprise), and onecriterion problem of optimization at different initial conditions was settled. Simultaneously the values of the rest criteria $F, K, A$ were calculated. A condition was added to the parameter $\delta$ values. According to the condition its level should not get lower than planned $4 \%$.

Thus, at the end of the first stage information collection was formed. It served as the basis for determining the best strategy for enterprise development from the point of view of compromise reaching via the criteria $F, K, A$. (The criterion $\delta$ was not taken into consideration at this stage, as in any variants its value was always maximum). At his stage the problem of determining the best strategy for enterprise development consisted in finding the best alternative. A method based on application of metric analysis was used for its solution (Kantor, 2009; Rodionova and Kantor, 2014).

Thus, at the first stage at different initial conditions the following problem was solved:

$\delta \rightarrow$ max

$\beta_{\mathrm{t}}^{1}=\frac{K_{\mathrm{t}}\left(\mathrm{n}_{\mathrm{t}-1}+(1+\delta)(\mathrm{i}+\mathrm{j})+\delta\right)-\alpha_{\mathrm{t}} A_{\mathrm{t}}-\mathrm{I}_{\mathrm{t}}}{P_{\mathrm{t}}}, \mathrm{t}=\overline{1, \mathrm{~T}}$

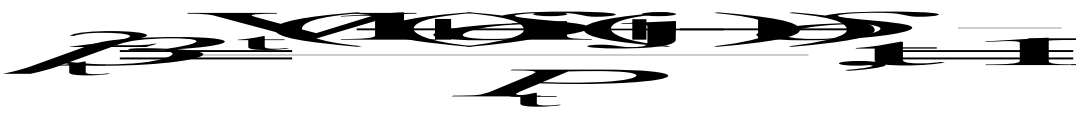



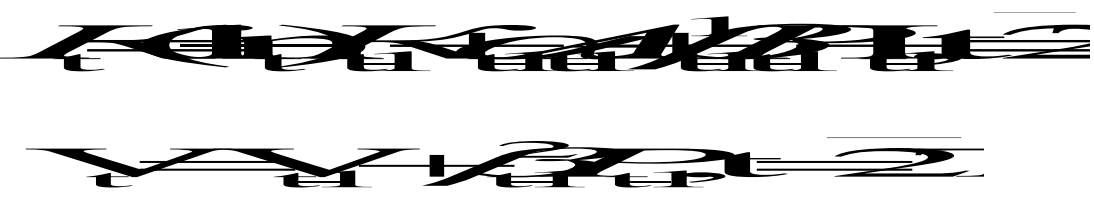

$P \geq Q \mathbf{Q}=\overline{\mathbf{1}}$

$\hat{\beta} \geq 0 \mathbf{0}=\overline{1 T}$

$13+t^{3}, 3,5 \overline{1]}$

$\delta \geq 0,04$

$\alpha \leq 0, \mathbf{q}=\overline{\mathbf{I}}$

In each case the criteria values were described:

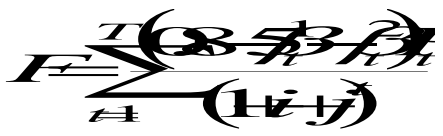

$K=\frac{K_{T}}{K_{1}}$

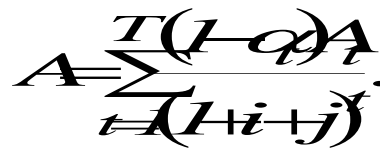

Table 3. Selected variants of problem solution (28-37)

\begin{tabular}{|l|l|l|l|l|l|l|}
\hline \multirow{2}{*}{$\begin{array}{l}\text { Varia } \\
\mathrm{nt}\end{array}$} & \multicolumn{2}{|l|}{ Variable values } & $\delta$ & $F$ & $K$ & $A$ \\
\cline { 2 - 3 } & $\mathrm{D}$ & Year & & \\
\hline
\end{tabular}




\begin{tabular}{|c|c|c|c|c|c|c|c|c|c|c|}
\hline & $\begin{array}{l}\mathrm{e} \\
\mathrm{s} \\
\mathrm{i} \\
\mathrm{g} \\
\mathrm{n} \\
\mathrm{a} \\
\mathrm{t} \\
\mathrm{i} \\
\mathrm{o} \\
\mathrm{n}\end{array}$ & 1 & 2 & 3 & 4 & 5 & & & & \\
\hline 1 & $\alpha_{t}$ & 0.70 & 0.80 & 0.80 & 0.80 & 0.80 & \multirow{2}{*}{0.21} & \multirow{2}{*}{45616.9} & \multirow{2}{*}{4.44} & \multirow{2}{*}{2966.4} \\
\hline$\alpha^{0}=0.8$ & $I_{t}$ & $\begin{array}{l}115493 \\
4 \\
\end{array}$ & $\begin{array}{l}1339 \\
61.8 \\
\end{array}$ & $\begin{array}{l}21028 \\
8.5 \\
\end{array}$ & $\begin{array}{l}36500 \\
5.0 \\
\end{array}$ & $\begin{array}{l}360013 \\
.8\end{array}$ & & & & \\
\hline \multirow{2}{*}{$\alpha^{0}=0.6$} & $\alpha_{t}$ & 0.60 & 0.00 & 0.00 & 0.60 & 0.60 & \multirow{2}{*}{0.08} & \multirow{2}{*}{66172.5} & \multirow{2}{*}{2.80} & \multirow{2}{*}{8680.8} \\
\hline & $I_{t}$ & $\begin{array}{l}83521 . \\
7 \\
\end{array}$ & $\begin{array}{l}1094 \\
05.1 \\
\end{array}$ & $\begin{array}{l}11734 \\
6.5 \\
\end{array}$ & $\begin{array}{l}14017 \\
8.9 \\
\end{array}$ & $\begin{array}{l}102844 \\
.0\end{array}$ & & & & \\
\hline \multirow{2}{*}{$\alpha^{0}=0.4$} & $\alpha_{t}$ & 0.40 & 0.40 & 0.40 & 0.40 & 0.40 & \multirow{2}{*}{0.05} & \multirow{2}{*}{67905.2} & \multirow{2}{*}{2.53} & \multirow{2}{*}{8069.7} \\
\hline & $I_{t}$ & $\begin{array}{l}74840 . \\
7 \\
\end{array}$ & $\begin{array}{l}6747 \\
4.1 \\
\end{array}$ & $\begin{array}{l}11827 \\
7.1\end{array}$ & $\begin{array}{l}11189 \\
1.7\end{array}$ & $\begin{array}{l}94734 . \\
0 \\
\end{array}$ & & & & \\
\hline \multirow{2}{*}{$\alpha^{0}=0.2$} & $\alpha_{t}$ & 0.20 & 0.20 & 0.20 & 0.20 & 0.20 & \multirow[b]{2}{*}{0.04} & \multirow[b]{2}{*}{72852.3} & \multirow[b]{2}{*}{2.44} & \multirow[b]{2}{*}{10759.5} \\
\hline & $I_{t}$ & $\begin{array}{l}75515 . \\
6\end{array}$ & $\begin{array}{l}8321 \\
3.3\end{array}$ & $\begin{array}{l}84187 \\
.9\end{array}$ & $\begin{array}{l}10338 \\
0.5\end{array}$ & $\begin{array}{l}100092 \\
.4\end{array}$ & & & & \\
\hline
\end{tabular}

The data of the last three columns in Table 3 were used during realization of the second stage.

Table 4. Determination of the enterprise development strategy on the basis of application of metrical analysis

\begin{tabular}{|l|l|l|l|l|l|l|l|}
\hline \multirow{2}{*}{ Variant } & \multicolumn{3}{|l|}{ Initial criteria values } & \multicolumn{3}{l|}{ Normalized criteria values } & \multirow{2}{*}{$d_{i}$} \\
\cline { 2 - 7 } & $F$ & $K$ & $A$ & $F$ & $K$ & $A$ & \\
\hline 1 & 45616.9 & 4.436 & 2966.4 & 0.00 & 1.00 & 0.00 & 0.82 \\
\hline 2 & 66172.5 & 2.801 & 8680.8 & 0.75 & 0.18 & 0.73 & 0.52 \\
\hline 3 & 67905.2 & 2.530 & 8069.7 & 0.82 & 0.05 & 0.65 & 0.60 \\
\hline 4 & 72852.3 & 2.439 & 10759.5 & 1.00 & 0.00 & 1.00 & 0.58 \\
\hline
\end{tabular}

Normalization coefficient $1 / \sqrt{3}$ serves for convenience of interpretation of results: each value $d_{i} / \sqrt{3}$ corresponds to the degree (and after 100-multiplication - to the percentage) of difference from the standard. The standard was taken as a hypothetical variant of organization of manufacturing process, at which the values of 
the criteria $F, K, A$ equal the maximum values of the available ones. Thus, the lower is $d_{i} / \sqrt{3}$, the closer to the standard the alternative is, and therefore, it is more preferable.

\section{Conclusion}

Basing on the considered results of application of metrical analysis for evaluation of the available alternatives (see the last column in Table 4), it may be concluded that the second variant of organization of production process reforming is the optimal from the point of view of the chosen method of problem solving. It should be noted that the obtained optimal solutions are characterized by large volumes of investments, which cannot be always provided. In this case the decision-maker may exclude such alternatives from consideration at the second stage as unsuitable a fortiori.

It is evident that variety of initial conditions during realization of the first stage will result in increase of the number of alternatives at the second stage, and therefore the decision-maker shall have more information in possession to make decisions relating to determination of the best strategy of production reforming.

The proposed two-stage procedure of determination of the optimal strategy for enterprise development with investments into production reforming on the basis of application of methods for multi-criterion problem solving enables making flexible decisions considering the interests of the enterprise and its emitters, thus striking a compromise in their contradicting interests.

\section{References}

Bredley, R.A. and Myers, S.C. (1997). Principles of Corporate Finance. Moscow: ZAO «Olymp-Business».

Brigham, Yu. and Gapenski, L. (2001). Financial Management: A Complete Course. Saint Petersburg: The school of Economics.

Easterbrook, F. (2010). The limits of antitrust enforcement. Economic policy, 5-6: 17-18.

Easterbrook, F.H. (1984). The Limits of Antitrust. Texas Law Review, 63: 1-41.

Gitman, L.G. (2009). Principles of managerial finance. 12th ed. Prentice Hall.

Grullon, G., Michaely, R. and Swaminathan, B. (2002). Are Dividend Changes a Sign of Firm Maturity? The Journal of Business, 75: 3.

Guliamov, S.S. (2006). Legal problems of the distribution of profits in subsidiaries of the company. Legislation, 2: 50-56.

Handjinicolaou, G. and Kalay A. (1984). Wealth Redistributions or Changes in Firm Value: An Analysis of Return to Bondholders and the Stockholders around Dividend Announcements. Journal of Financial Economics, 13(1): 35-63.

Ivanov, A.N. (1996). Capital management and dividend policy. Infra-M.

Kantor, O.G. (2009). Metric Analysis to assess the development of the territories. Economic Development of Regions: Proceedings. Part 6. Ufa: Publishing House "Dialogue". 
Kobets, E.A. (2006). Planning for the Enterprise. Tutorial. Taganrog: Izd.TRTU.

Lee, C.F. and Finnert, J.E.. (2000). Finance Corporation: Theory, Methods and Practice. INFRA-M.

Lintner, J. (1964). Optimal Dividends and Corporate Growth Under Uncertainty. The Quarterly Journal of Economics, 78(1): 49-95.

Litzenberger, R.H. and Ramaswamy, K. (1979).

The Effect of Personal Taxes and Dividends on Capital Asset Prices: Theory and Empirical Evidence. Journal of Financial Economics, 7(2): 163-195.

Miller, M. and Modigliani, F. (1961). Divident Policy, Growth, and the Valuation of Shares. Journal of Business, 34(4): 411-433.

Modigliani, F. and Miller, M. (1958). The Cost of Capital, Corporation Finance and the Theory of Investment. American Economic Review, 48: 261-297.

Oberbrinkmann, F. (2003). Current understanding of the balance sheet. Finance and Statistics.

Podinovskiy, V.V. and Gavrilov, V.M. (1975). Optimization for consistently applied criteria. Soviet radio.

Rishar, J. (2000). Accounting: Theory and Practice. Finance and Statistics.

Rodionova, L.N. and Kantor, O.G. (2014). Balance indicators in assessing the competitiveness of products. The region's economy, 3: 257-265.

Shulga, A. (2008). How to manage finances in a crisis. General manager. Personal manager magazine, 12: 14-22.

Sosnauskene, O.E. (2006). Profit optimization. Exam.

Stern, J. (1974). Earnings per Share Don't Count. Financial Analysts Journal, 30(4): 39-43. 